\title{
SAÚDE DA FAMÍLIA FLUVIAL: LONGITUDINALIDADE NA PERSPECTIVA DE USUÁRIOS RIBEIRINHOS
}

Wellington Pereira da Silva Graduando de Enfermagem, FEnf Unicamp wellingt27@gmail.com

INTRODUÇÃO: o Ministério da Saúde instituiu, visando ampliar o acesso e que pudessem atingir regiões mais difíceis, as Equipes de Saúde da Família Fluviais (ESFF) e Ribeirinhas, priorizando a população ribeirinha da Amazônia Legal e Pantanal Sul-mato-grossense1. OBJETIVO: avaliar a longitudinalidade nas ESFF na perspectiva de usuários ribeirinhos. MÉTODO: pesquisa avaliativa, transversal e quantitativa, com dados coletados pelo PCATool adulto versão reduzida2, realizada no município de Santarém - Pará, com população de 294.447 habitantes3. A amostra foi de 342 participantes, com coleta realizada nas viagens das equipes. $O$ escore foi calculado pela média aritmética dos valores das respostas em escala de 0 a 10. Consideraram-se altos os valores $\geq 6,64$. As análises foram pelos softwares estatísticos SAS versão 9.4 e o SPSS versão 22. Comitê de Ética: oํ 2.079 .984 de 24/05/2017. Resultados: a longitudinalidade, obteve escore de 6,94, considerada satisfatória, considerando que os usuários têm as equipes como fonte regular dos cuidados, porém percebeu-se a frequente rotatividade dos profissionais das equipes. CONCLUSÃO: identificou-se que a longitudinalidade alcançou avaliações satisfatórias demonstrando a valorização do serviço, que apesar de escasso, é a opção encontrada para o atendimento das necessidades em saúde das comunidades.

Palavras-chave: Atenção Primária à Saúde. Avaliação em Saúde. Estratégia Saúde da Família. 